\title{
Phase bowndaries and domain boundaries in crystals
}

\author{
H KLAPPER, TH HAHN' and H-D JENNISEN' \\ Mineralogisches Institut, University of Bonn, D-5300 Bonn, 'Instilut fuer K, ristallographie der \\ RWTH Agchen, D-5100 Aachen, Germany
}

Abstract. Domain boundaries, i.e. intertaces berween different orientation variants of the same crystal species, and phase boundan ies, i.e. interfaces betwecr two different modifications of the sarne compound, exhibit rather similar features. This has been investigated by means of polatized light and X-ray topography for a series of structurally telazed sulphates which were grown as lurge single crystals from ay ueous solution. The major ressults are as follows:

(i) Domain interfaccs ircquently adopted only a few orientations which are low-energy bourdarles of best structural fit. These preferred orientations may be parallel to low-indexed lattlee planes or to non-crystailographic planes ( $W$ and $W^{\prime}$ walls according to the classiffeation of Sapriel, Phys. Rev. B12, 1975, 5128). Ilustrations of such (transition-induced) domain boundaries in $\mathrm{KLiSO}_{4}, \mathrm{NH}_{4} \mathrm{LiSO}_{4}, \mathrm{RbLiSO}_{4}, \mathrm{CsLiSO}_{4},\left(\mathrm{NH}_{4}\right)_{3} \mathrm{H}\left(\mathrm{SO}_{4}\right)_{2}$ wilt be presented. (ii) For many iirst-order transitions the phase boundarjes prefer planes of minimum strains, i.e. low energy, which again may be low-index lattice plates or non-crystallographic planes. These preferred orientations can be calculated from the strain tensor of the transition with the rejative lattice-parameter changes as tensor components). If the transition isotherm devittes from the minimum strain orientation, characteristic rigzag boundaties with segncnts parallel to the (symmetrically equivalent) pteferred planes may result. Zigzag phase boundaries have been observed in $\mathrm{RbLiSO}_{4}$ and $\left[\mathrm{N}_{(\mathrm{CH}} \mathrm{CH}_{4}\right\}_{2} \mathrm{ZnCl}$.

(iij) The shape and the density of transition-jncuced domains is influenced by the orientation of the phase boundaries and its velocity of motion. For the $708 \mathrm{~K} \mathrm{transition} \mathrm{of} \mathrm{KLiSO}_{4}$ and the $413 \mathrm{~K}$ transition of $\left(\mathrm{NH}_{4}\right)_{3} \mathrm{H}\left(\mathrm{SO}_{4}\right)_{2}$ (in both eases loss of the trigonal axis), arnong the minmulm-strain domain boundaries those normal to the phase boundary are preferrod, In $\left[\mathrm{V}_{(\mathrm{CH}} \mathrm{CH}_{4}\right]_{2} \mathrm{ZnCl}_{4}$, the domain density increases with the phase boundary velocity. 